\title{
AN EVALUATION STUDY ON AUTOMATIC SUPERVISING SYSTEMS FOR ROAD FACILITIES
}

\author{
Muneo Momozawa \\ Hanshin Expressway Management Technology Center \\ Toa Bldg. 4-5-7, Minami-honmachi, Chuo-ku, Osaka 541-0054, Japan \\ momozawa@tech-center.or.jp
}

\begin{abstract}
Various systems, such as traffic-control system, and road facilities management system, are installed on the Hanshin Expressway to secure the safety, smoothness, and comfort of travelling in motor vehicles. The effective utilization of these systems can only be supported by the proper operation of various items of equipment comprising each of these. From the standpoint of efficiently operating, and managing the various facilities, I have conducted a study evaluating the precedence of introducing equipment data items subject to measurement by Absolute Measurement Method, a type of the Analytic Hierarchy Process.
\end{abstract}

\section{Introduction}

To alleviate traffic congestion and ensure the smooth flow of urban traffic according to fixed-speed and time-schedules, and to realize or secure the safety, smoothness, and comfort of travelling in motor vehicles, various systems are equipped on The Hanshin Expressway. These systems, such as traffic control system, toll management system, road facilities management system, etc., support road traffic management operations to maintain the functions of roads. The effective utilization of these systems can only be supported by the proper operation of various items of equipment comprising each of these. It may be said that automatic monitoring of the operating state of equipment with sensors and equipment data management are the essential stay of these systems mentioned above. Also, from the stand point of efficiently operating, maintaining, and managing the various facilities of The Hanshin Expressway, we have needed a method of quantitatively evaluating the precedence of introducing equipment data items subject to measurement by giving an example of the evaluation.

In keeping pace with trends in sensor technologies, we used empirical methods to make improvements in the introduction of items subject to equipment data sensing. It was necessary that we quantitatively reassess by degree of preference the items to be introduced for equipment data sensing. It was necessary for us to do this at a time when there was mounting demand for more advanced functions to manage and maintain growing quantities of equipment whose quality was being enhanced.

With respect to the facilities for the Hanshin Expressway, we therefore extracted equipment data items that were deemed necessary for facilities, irrespective of whether they had already been introduced. These items were extracted with the following aims in mind:

1 Accurately grasping the operating state of each item of equipment

2 Quickly grasping the condition of any accident

3 Preventing accidents from occurring

4 Making inspection and maintenance operations more efficient

To reassess by degree of preference data items to be introduced for equipment management, we examined the greater appropriateness of their introduction by making the best use of the Absolute Measurement method, a variation of the conventional Analytic Hierarchy Process (AHP) method. Because we must reassess as many as 386 items of equipment data in this examination, we thought it difficult to apply the conventional method.

For purposes of discussion, power receiving and distributing equipment is explained in this paper to avoid 
confusion.

\section{Evaluation study on the introduction of equipment data}

\section{Equipment data extraction}

Equipment for the Hanshin Expressway is finely monitored at all times for proper operation with a system, which if an equipment fault occurs, immediately informs person(s) in charge of monitoring (hereafter referred to as monitoring personnel) of the status and nature of the fault through its alarm and information display functions. Along with the recent advances in sensor and information processing technologies and based on the data accumulated through such equipment maintenance efforts, the Hanshin Expressway Public Corporation (HEPC) has been putting forward the gradual introduction of systems for automatic status monitoring and equipment diagnosis which can detect symptoms of equipment failures and perform trend analysis of symptoms leading to equipment failures, with the aim of carrying out the maintenance and management of equipment at more advanced levels.

It was natural for the needs of solving problems attributable to such background factors to arise. Figure 1 shows a system schematic diagram illustrating "Background" (causes of system introduction), "Needs" of solving the problems, and "Actions" for solving the problems.
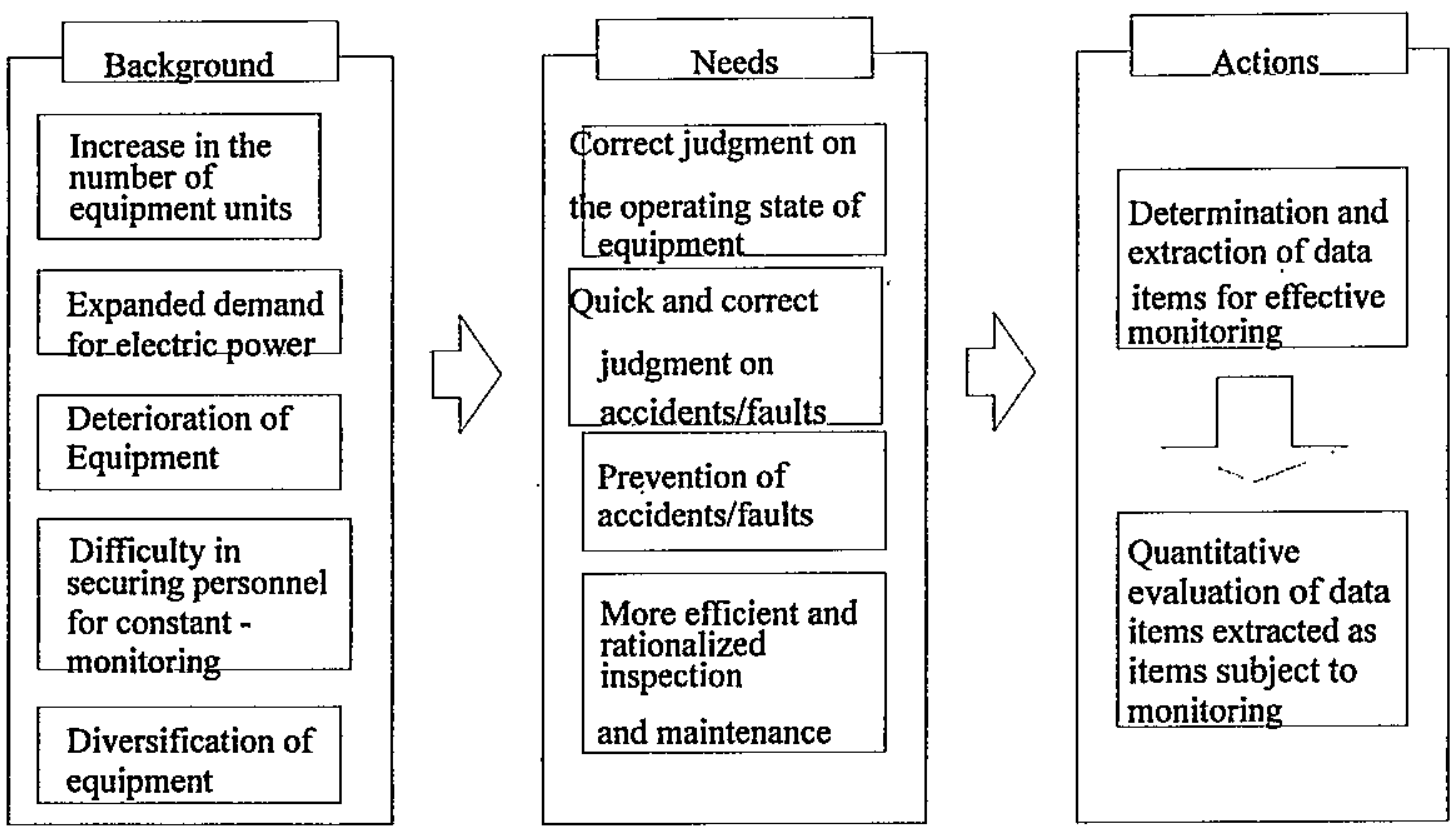

Figure 1 System schematic diagram

As actions for fulfilling these needs, we decided to review, determine, and extract equipment data items for effective sensing (monitoring) and to perform quantitative evaluation on all of the extracted items.

To carry out these operations, we investigated each of the existing facilities to grasp the current conditions of equipment data that had already been introduced into the facility and decided to subject to extraction all equipment data items deemed necessary, including data items of equipment yet to be introduced. As a result, the number of equipment data items extracted from those related to power facilities (power receiving and distributing equipment) amounted to as many as 386 .

\section{Quantitative evaluation}

The extracted 386 items were subjected to quantitative evaluation using the Absolute Measurement 
method. First, we selected the following four basic items as evaluation criteria:

1 Event occurrence (how often an event occurs)

2 Subject or extent of influence (what is affected or to what extent it is affected)

3 Practicability

4 Effect of investment

Because elements to be evaluated by criteria 2 and 4 can be subdivided, we decided to handle such elements using a hierarchical structure and to place the following items at a level immediately lower than that of criteria 2 and 4:

Subject or extent of influence: Casualty, equipment, electric power supply

Cost, labor conservation in maintenance, safety improvement

The overall objective of the problem (that is, to reevaluate equipment data) was placed at the top level of the structure and the 386 items of equipment data were placed as alternatives at the bottom level of the structure. Figure 2 shows the hierarchical structure of our problem-solving process.

Based on this hierarchical structure, we took the following mathematical approach: First, the elements of each level are weighted against each other. That is, pair comparisons among the elements of a line (at the same level) are determined in accordance with the evaluation criteria and the elements of the immediately higher level.

From the pair comparison matrices thus obtained for each level, weights among the elements of each level are calculated. (The mathematical background of this method is based on the concept of eigenvalues in linear algebra.)

Next, using the above results of weight calculation among the elements of each level, the entire hierarchy is weighted. The sum of the weighted values at the final level (the lowest level of the hierarchy) should become 1 , meaning that the value has been normalized. The weighted values themselves are.evaluation criteria as viewed from the overall objective (that is, equipment data revaluation).

The next process is to evaluate the degree of importance of equipment data (with respect to all $386 \mathrm{items)}$ in view of each evaluation criterion at the final level. The result is converted into the judgment value of each item. The judgment values of all items are obtained in this manner.

Weighted values for levels 2 and 3 are determined based on required operations by an assessor who has an abundance of know-how and experience in the field concerned.

How we actually completed the quantitative evaluation of equipment data items subject to introduction for effective maintenance is indicated in Figure 2, Evaluation elements and criteria. 


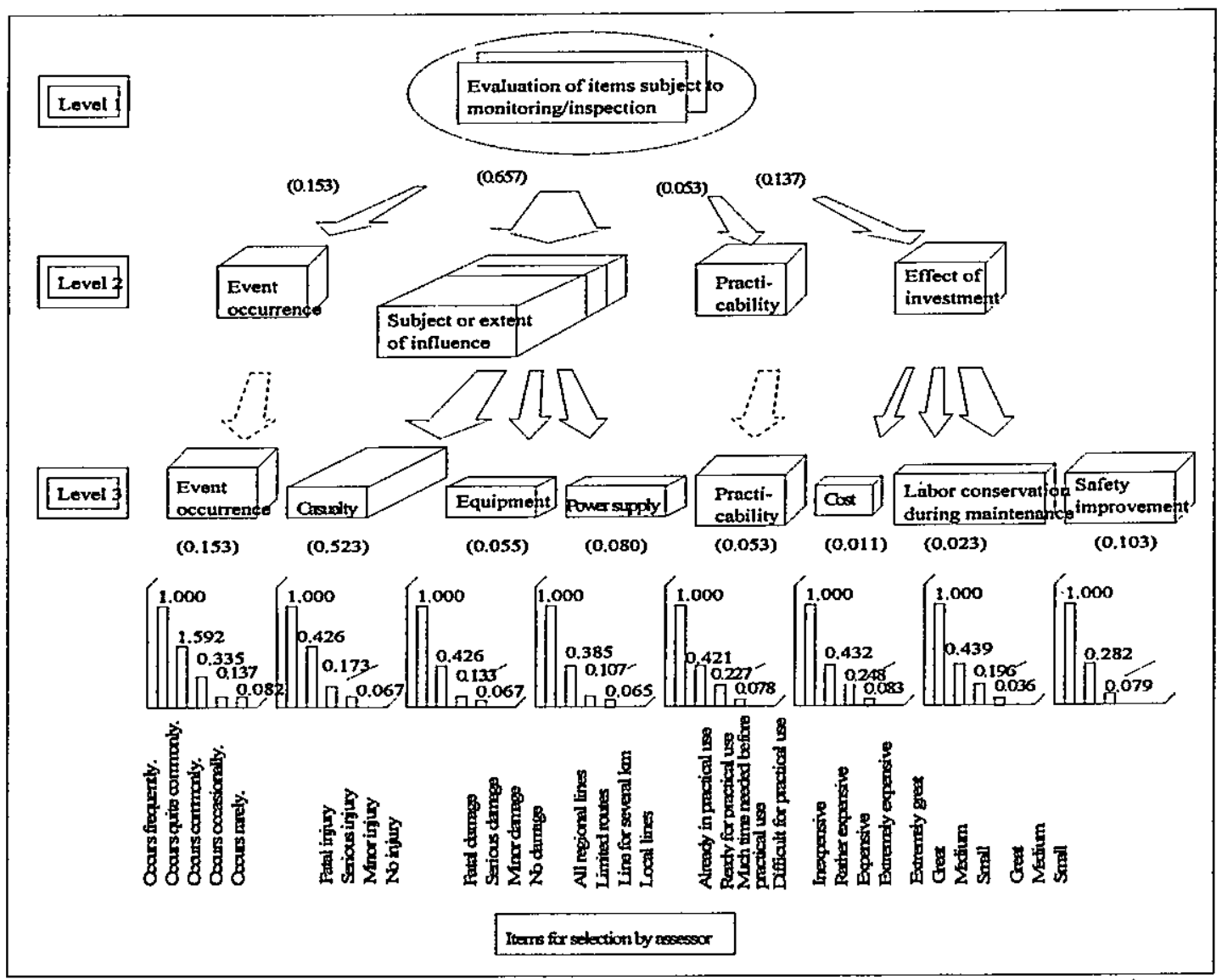

Figure 2 Evaluation elements and criteria

\section{Result}

The results of our overall review of the evaluation scores of all equipment data were as follows:

1. With the highest rank given to all evaluation criteria, the evaluation score of a data item became 1,000 points. With the lowest rank given to all evaluation criteria, the evaluation score of a data item became 70 points.

2. Of the $\mathbf{3 8 6}$ items, the following items earned the highest or lowest score:
Highest score
"Power receiving equipment breaker" among operation monitoring data: 884 points
"Generator breaker" among operation monitoring data:
884 points
Lowest score
"Humidity inside switch-gear" among maintenance data: 86 points.

The evaluation scores of all data items cannot be introduced here as space is limited on this paper. Figure 3 shows the distribution of evaluation scores (in descending order) from the highest to the lowest point. Also, Table 4.1.5 shows part of the evaluation scores given to individual equipment data items. 


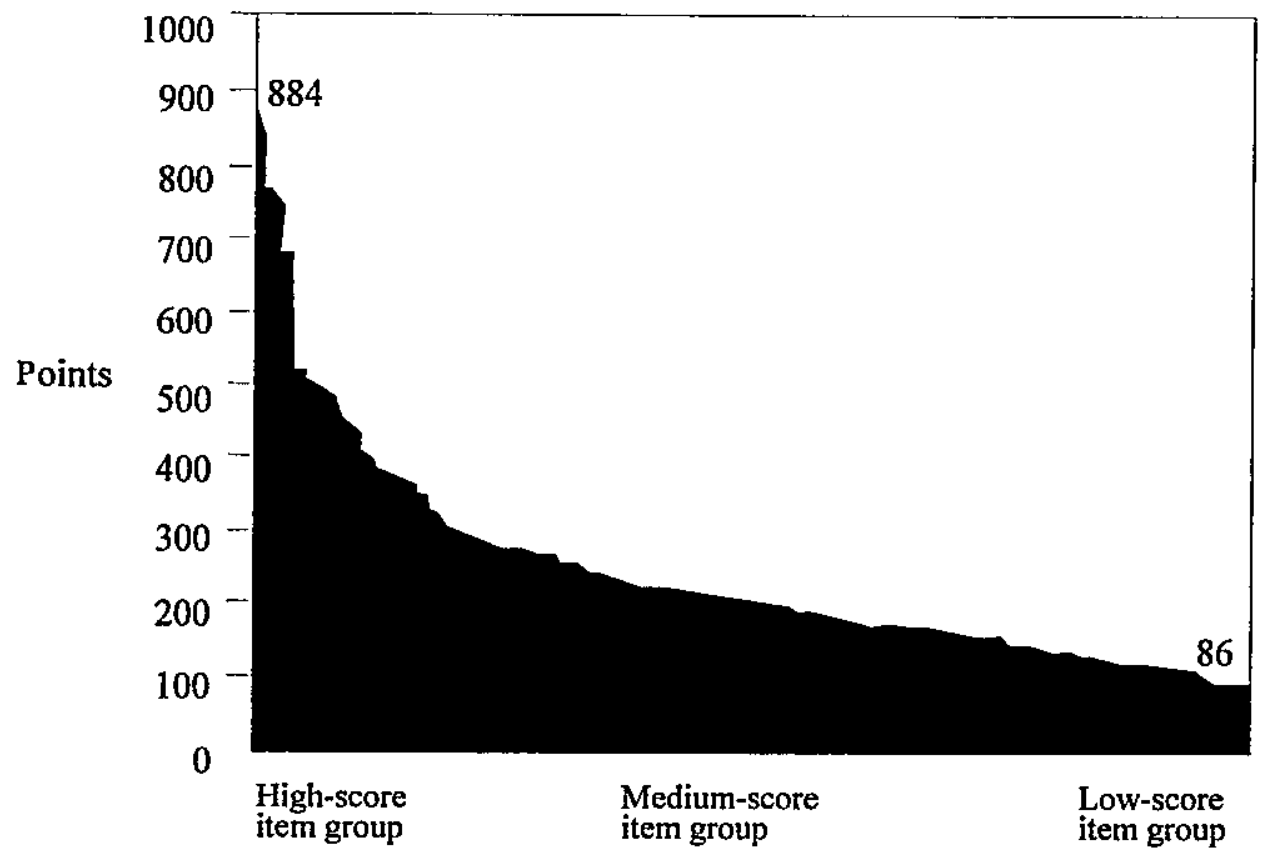

Figure 3 Distribution of the evaluation scores of all equipment data items (in descending order)

\section{Observations}

Before stating our observations of individual equipment data items, I would like to sum up this evaluation study on the introduction of equipment data items. We were able to state the following:

1. In the item group yet to be introduced, some items had a considerably high score.

2. All items extracted with a view to satisfy the needs of "more efficient and rationalized maintenance inspection" and "prevention of accidents or faults " were yet to be introduced but their evaluation scores were generally low.

From the results of quantitative evaluation we conducted in this manner, we can look forward to being able to provide support to the item selecting operation in the introduction of equipment data items in the future.

Next, as regards our observations of individual equipment data items, I would like to report the following with respect to the power receiving and distributing equipment in the power system facilities.

\section{Operation monitoring}

From the results of our evaluation on equipment data items subject to operation monitoring, we found that items related to the operation control of the main equipment in the power system facilities ranked higher (1st to 11th places) in terms of evaluation score, those related to the operation status of main equipment (for measurement of various electrical quantities) ranked middle (12th to 26th places), and those related to auxiliary system equipment ranked lower (29th place or lower).

Almost all items ranked middle or higher in terms of evaluation score were those already introduced with the exception of the items yet to be introduced shown in Table 1 below. These items were extracted from the aspects of operation, maintenance, accident prevention, and other needs. We feel that these items should be introduced in the future on a preferential basis. 
Table 1 Examples of ranks and evaluation scores of items subject to operation monitoring

\begin{tabular}{|l|l|l|l|}
\hline Item & Rank & Score (points) & Reason for extraction \\
\hline $\begin{array}{l}\text { Direct + door } \\
\text { shut alarm }\end{array}$ & 80 & 400 & $\begin{array}{l}\text { To prevent accidents or to satisfy the } \\
\text { operator's needs }\end{array}$ \\
\hline $\begin{array}{l}\text { GTR, primary } \\
\text { LBS }\end{array}$ & 20 & 241 & $\begin{array}{l}\text { To accurately grasp the operating state } \\
\text { of equipment }\end{array}$ \\
\hline $\begin{array}{l}\text { Load limiting } \\
\text { MC }\end{array}$ & 24 & 212 & $\begin{array}{l}\text { To accurately grasp the operating state } \\
\text { of equipment or to effect control for } \\
\text { energy conservation }\end{array}$ \\
\hline PAS for lead-in & 24 & 212 & $\begin{array}{l}\text { To accurately grasp the operating state } \\
\text { of equipment }\end{array}$ \\
\hline
\end{tabular}

\section{Fault monitoring}

From the results of our evaluation on equipment data items subject to fault monitoring, we found that Items related to major faults (serious damage) in main equipment in the power system facilities ranked higher (1st to 10th places) in terms of evaluation score, those related to minor faults in main equipment ranked middle (11th to 18th places), and those related to faults in auxiliary system equipment ranked lower (19th place or lower). Most of these items were already introduced. However, there were many equipment units subject to monitoring under the same data item as they were subject to collective monitoring. To grasp data on fault locations quickly and in detail, we need to look into the future introduction of these items as equipment data subject to monitoring on an individual unit basis.

\section{Preventive maintenance and automatic inspection}

Quite a few data items in this category are concerned with technologies currently being developed. The items shown in Table 2 below were extracted by reason of their being a direct hindrance to the power supply in the event of an abnormality or fault in the equipment or of their satisfying the operator's needs. These items earned a relatively high evaluation score. We also need to look into the future introduction of these items

Table 2 Examples of ranks and evaluation scores of items subject to maintenance and inspection

\begin{tabular}{|l|l|l|l|}
\hline \multicolumn{2}{|c|}{ Item } & \multicolumn{1}{c|}{ Rank } & \multicolumn{1}{c|}{ Score (points) } \\
\hline \multirow{2}{*}{$\begin{array}{l}\text { Preventive } \\
\text { Main- } \\
\text {-tenance }\end{array}$} & Detection of proximity to live parts & 1 & 317 \\
\cline { 2 - 4 } & Insulation monitoring of high-tension cable & 2 & 289 \\
\cline { 2 - 4 } & Insulation monitoring of transformer & 6 & 252 \\
\cline { 2 - 4 } & GIS or partial discharge in gas & 8 & 221 \\
\cline { 2 - 4 } & Overheating in panel & 9 & 213 \\
\hline \multirow{3}{*}{ Inspection } & Power receiving and distributing sequence & 4 & 231 \\
\cline { 2 - 4 } & $\begin{array}{l}\text { Vacuum leakage monitoring in circuit } \\
\text { breaker }\end{array}$ & 6 & 211 \\
\hline
\end{tabular}

$\mathbf{n}$ the above discussion, our observations of only the power receiving and distributing equipment in the power system facilities have been introduced. We conducted similar evaluation and analysis on other equipment in the power system facilities such as in-house engine generator equipment for emergencies, un-interruptible power supply equipment, and power substation equipment, as well as communications system facilities. 


\section{Summary}

In the case evaluation study using the Absolute Measurement method, a variation of the AHP method, we limited equipment data items to those subject to automatic inspection and monitoring in the power system among the various facilities ancillary to the Hanshin Expressway, an urban expressway and conducted quantitative evaluation on a number of items extracted. The evaluated values obtained in this study are neither absolute nor invariable over an extended period in the future. In other words, this evaluation method is used for evaluation under certain conditions as discussed previously. Therefore, evaluation criteria or factors are subject to change in accordance with the background to, or objects that surround the power system facilities of the urban expressway and the process of evaluation itself which may change qualitatively.

From a social standpoint, for example, should economic conditions become harsh, the element "effect of investment" would be affected greatly, with the assessor attaching importance to cost when evaluating data items. As regards the element "subject or extent of influence," should the assessor attach significant importance to a social effects such as by a serious accident, such factor would be reflected in the result (evaluated value). By this evaluation method, the result of the evaluation can be said to have flexibility sensitive to the social environment in which the assessor has been placed. Therefore, with this method, we can look forward to evaluations adaptable to social conditions, environmental problems, and other prevailing conditions.

As discussed above, by using this method, we converted into values qualitative data items not represented originally by any values and evaluated them. Doing so afforded us an opportunity to look into relationships among facilities and equipment comprising a system from viewpoints different from those in the past. This, in turn, has opened a way to the possibility of applying or expanding this evaluation method to other related fields without any difficulties surrounding practical operations. Furthermore, from the results of the case evaluation study, we were able to find new things from which we could grasp the existing trends and characteristics of equipment data. At this time, we are not simply confining this method to the evaluation of equipment data items. Rather, we are applying such qualitative evaluation method to the analysis of the entire Information provision system for road traffic management on the urban expressway. Accordingly, as was mentioned earlier, we look forward to the time when the quantitative evaluation method can contribute further to securing safe, smooth, and comfortable travel for expressway users.

\section{References}

M, Momozawa. E, Kinosita. and A, Nakagawa.(1996) "A Study on Evaluation of Automatic Check and Watch System for Facilities of Expressway" Expressway and Automobile, Vol.39, No.5,20-27.May.1996 